Journal of Trauma and Dissociation 18(5):710-719, 2017

\title{
Acute Dissociative Reaction to Spontaneous Delivery in a Case of Total Denial of Pregnancy: Diagnostic and Forensic Aspects
}

\author{
Vedat Şar MD, Nazan Aydın MD, Onno van der Hart PhD, A. Steven Frankel JD, PhD, \\ Meriç Şar LLB, LLM, \& Oğuz Omay MD
}

\begin{abstract}
This article presents the history of a 21-year-old female college student with total denial of pregnancy who experienced an acute dissociative reaction during the spontaneous delivery at home without medical assistance where the newborn died immediately. Psychiatric examination, selfreport questionnaires, legal documents, and witness reports have been reviewed in evaluation of the case. Evidence pointed to total denial of pregnancy, i.e. until delivery. The diagnoses of an acute dissociative reaction to stress (remitted) and a subsequent PTSD were established in a follow-up examination conducted seven months after the delivery. Notwithstanding the inherently dissociative nature of total denial of pregnancy, no other evidence has been found about preexisting psychopathology. For causing the newborn's death, the patient faced charges for "aggravated murder," which were later on reduced into "involuntary manslaughter". Given the physical incapacity to perform voluntary acts due to the loss of control over her actions during the delivery, and the presence of an acute dissociative reaction to unexpected delivery, the legal case represents an intricate overlap between "insanity" and "incapacitation" defenses. The rather broad severity spectrum of acute dissociative conditions requires evaluation of the limits and conditions of appropriate legal defenses by mental health experts and lawyers. Denial of pregnancy as a source of potential stress has attracted little interest in psychiatric literature although solid research exists which documented that it is not infrequent. Arguments are presented to introduce this condition as
\end{abstract}


a diagnostic category of female reproductive psychiatry with a more neutral label: "unperceived pregnancy."

Keywords: pregnancy, dissociation, denial, forensic, neonaticide

"Denial of pregnancy" is defined as not recognizing the condition until the 20th week after conception. In the case of total denial, the pregnancy is not perceived till delivery neither by the woman, nor her partner, nor her parents, in some cases not even by her doctors. Denial of pregnancy, when total in particular, can lead to a traumatic delivery, loss of newborn, and medical and psychiatric complications alongside forensic consequences. Pregnancy denial has not attracted sufficient attention in the psychiatric literature despite the existing solid epidemiological research concerning this phenomenon. Partial denial of pregnancy occurs in approximately one of 500 pregnancies (Wessel \& Büscher, 2002). In one of 2500, denial of pregnancy continues until delivery (total denial). Aydin (2013) reported a series of seven cases (including one total denial) between 18 and 38 years of age. For 6 of them, it was the first pregnancy. In a recent epidemiological study in Turkey (Aydin, 2015), partial denial was reported in 1/526 (0.19\%) of all pregnancies. Of the 30 identified cases (age range 18-46; 1-6th pregnancy), none of them had a psychotic disorder.

Such dramatic but non-psychotic denial may be related to dissociation (see MacFarlane, 2016), which involves a disruption of and/or discontinuity in usually integrated mental functions such as consciousness, memory, identity, emotion, perception, body representation, motor control, and behavior (American Psychiatric Association, 2013). Dissociation is involved in a broad spectrum of trauma-related disorders as a main component of psychopathology (Şar, 2011). Such mental disruption can lead both to a chronic and acute dissociative disorders. The latter can transiently lead 
to disorganized behavior involving diminished awareness of oneself and the environment. In the present article, a special emphasis is placed on the forensic aspects of the acute dissociative reaction -a new diagnostic category in DSM-5 listed among other specific dissociative disorders- to unexpected delivery, which ended with the loss of the newborn. This study also aims raising awareness s about denial of pregnancy - a little known phenomenon--as a potential source of acute traumatic stress. Considering its potentially complex and multi-factorial aetiology, we suggest a more neutral name for this condition: "Unperceived pregnancy."

\section{CASE PRESENTATION}

The patient/client has given informed written consent for the publication. Her identity has been disguised by omission and alteration of non-crucial information. The older one of three siblings, Maria (pseudonym) was a 21-year-old female exchange student from western Europe temporarily located in Istanbul. Without being aware of her pregnancy, she gave birth to a child in the third month of her stay in Turkey. The child died during the unexpected spontaneous delivery at home with no medical assistance.

Maria was living in an apartment house shared by college students then. She was described by her friends as a cheerful, socializing girl with a warm attitude and no behavioural problems. Her grandfather passed away six months prior to her arrival in Istanbul, with whom she was in a close

relationship. She has had a boyfriend for five years, who was the father of the newborn according to Maria's report.

\section{Unperceived Pregnancy}

Maria's last menstruation occurred approximately 8-9 months prior to the delivery. She additionally had two menstrual periods lasting shorter than usual (only two days). She interpreted this irregularity as a side effect of the contraceptives, which she stopped taking after coming to Turkey. She had nausea a few times in early stages of the pregnancy, which she associated with frequent alcohol consumption. Maria related her mild overweight to eating and drinking in student 
parties she frequently attended. When pictures of that period and those taken in the pregnancy period were compared, she looked, paradoxically, more overweight in the former. Neither she herself nor her friends and parents realized that she was pregnant.

\section{Delivery and Acute Dissociative Reaction}

Maria woke up due to abdominal pain during midnight. Taking this as a sign of menstrual period, she got a shower. As she felt abdominal pressure, she repeatedly visited the restroom afterwards and tried to defecate. Due to the on-going bleeding and abdominal pain, she woke up her friends towards early morning and asked for assistance. According to the witness' reports, she was frantic in behaviour and her facial expression reflected severe pain. Sitting on the water closet, she examined her vulva with her hand. She said that she "touched something hard inside" and screamed: "something is coming out of my body." While she stood up, a newborn in pallor and violet color fell into the water closet. Being puzzled, Maria screamed and left the bathroom while the umbilical cord, disrupted due to her hectic movements, was hanging below. In order to stop bleeding, Maria's friends assisted her in putting a towel to her vulva. When Maria took the towel out shortly afterwards, her placenta fell to the floor.

According to her friends, she was looking like "crazy" at that time and started to scream again. She repeatedly said, "this cannot be true," "something is wrong." Presenting a dissociative state, she was "shocked," confused, and entered in a transient stupor ; she did not respond to comments of her friends. Her dissociative, disorganized behavior lasted approximately one hour; i.e., until arrival of an ambulance. She was transported to a hospital. Police officers and ambulanciers found the fully developed dead newborn in the water closet with its head inside of the water.

\section{Follow-Up and Psychiatric Examination}

According to her friends, she was upset and crying continuously for days after the event. She was asking, "why did I not recognize what occurred in my body?'” Temporarily demonstrating 
lack of realization, she could not give any meaning to the milk coming out of her breasts. According to her lawyer's report, Maria repeatedly stated that she could not remember what happened during and immediately after delivery. Moreover, she continued to have micro-amnesias which interfered with her daily functioning (e.g., forgetting her appointments).

A psychiatric evaluation was ordered by the state attorney upon request by the defendant's lawyer, which was carried out by two female psychiatrists seven months after the delivery. One of the examiners (N.A.) was serving as the chief physician of a general psychiatric clinic in the largest state mental hospital in Istanbul (a professional training and research institution) and as the head of the Women's Mental Health Center affiliated with the same hospital. The second expert was an attending psychiatrist of the latter center. Maria was diagnosed as having had a total pregnancy denial, described by Van der Hart et al. (1991) as "non-realization," acute dissociative reaction (remitted), and posttraumatic stress disorder (current). She still had partial dissociative amnesia to the delivery and to her reaction. The Dissociative Experiences Scale (DES) (total=4.3 with a possible range of 0-100) and Somatoform Dissociation Questionnaire (total=30, with a possible range of 20-100) scores were below the cut-off level for chronic complex dissociative disorders.

\section{The Trial: Insanity or Incapacitation?}

Under Turkish criminal law, defenses related to "mental capacity" are recognized as affirmative defences which can only be raised during trial. Thus, the predominance of the psychiatric question in Maria's case led the state attorney initiate a file without consideration of Maria's mental status in the preliminary phase of the case. Maria was initially charged with aggravated murder for "intentionally killing a child or a person who is mentally or bodily incapable to defend himself," and a travel ban was pronounced by the court until further proceedings. During the investigation, the state attorney requested psychiatric examination of Maria by a team of two psychiatrists, who were also given the task of answering four medico-legal questions: 1) the medical possibility of pregnancy denial; 2) whether the accused person's status fitted this 
condition; 3) whether the accused person demonstrated the behaviour reasonably expected in such condition; 4) whether and how the accused person's status of "shock" affected her consciousness (whether one may expect from her the capability of undertaking any necessary assistance to the newborn). The psychiatric examiners stated that denial of pregnancy was medically possible, and the physical incapacitation arising from an acute dissociative reaction to the unexpected delivery could have rendered Maria's acts as involuntary in relation to the failed delivery.

In response to this opinion, the judge lifted the prohibition of leaving the country during the preliminary hearings and revised the charge as "involuntary manslaughter". The judge ordered a more holistic forensic medical inquiry by the court's medical referee (i.e., medical experts' panel of the State Institution of Forensic Medicine) to determine Maria's degree of responsibility in the action causing the death of the newborn in consideration of the entirety of relevant factors (i.e. including Maria's mental conditions). This request was rejected by the court's medical referee as improperly formulated. In the medical referee's opinion, the court's request was erroneous and unusual as it demanded a graded estimation in relation to the defendant's mental capacity. It was common for the forensic authority to issue such graded reports in relation to causality-related inquiries regarding material events, however, such a graded opinion would be improper in determining mental incapacity or insanity.

\section{DISCUSSION}

\section{Legal Aspects}

The already traumatic delivery led to a judicial process that added further distress to the affected person and a major challenge to forensic experts. Namely, Maria's non-realization prior to, and panic during delivery led to a criminal prosecution for "murder" which was later reduced into “involuntary manslaughter" based on an initial psychiatric review, which supported the view that Maria was likely to be suffering from "pregnancy denial." From a legal standpoint, the loss of behavioural control during the delivery and the related acute dissociation can be seen as allowing 
both insanity as well as incapacitation defenses due to her inability to conduct voluntary acts during the delivery (MacFarlane,1998). Indeed, an acute dissociative reaction may involve disorganized behavior and may turn even to a brief psychosis (Sar \& Ozturk, 2008; Spiegel et al., 2011; Van der Hart \&Witztum, 2008) as mentioned in DSM-5 (p.292) as well. However, in cases involving acute dissociation, usually courts tend to be reluctant to acquit defendants under the generally accepted standards of the insanity defense due to the transient nature of the syndrome. A court would be more likely to accept the incapacity defense in a case involving severe physical incapacity and duress caused by an objectively incapacitating event such as the delivery of a child.

Indeed, the case represents an interesting conundrum from a legal standpoint. Assuming that the patient suffered from pregnancy denial (and thus did not carry the requisite specific intent to cause the death of the newborn), the difficulty in dissecting the applicable legal norms arises from the apparent coexistence of both insanity (due to acute dissociation) and physical incapacitation (due to the mother's physical incapacitation during birth). The judge's intuitive awareness of this tension seems to have led the court to proceed with a more holistic inquiry on "causality" by downplaying the role of acute dissociation and the related insanity defence. Another reason for the court's hesitation in framing the issue solely as a matter of "insanity" can be the onerous conditions associated with the sentencing of individuals who successfully plead an insanity defence and the likelihood of defendant's incarceration at a psychiatric facility regardless of being found not guilty due to mental insanity. In the court's mind such hospitalization can be avoided only by assignment of the psychiatric condition as a transient impact factor in a situation of general incapacitation due to multiple coexisting causes. The immediate reaction to the unexpected delivery was relatively transparent in consideration of the presence of eyewitnesses; hence, simulation or intended murder can be considered as ruled out for the presented case.

It is well established in the USA law that insanity defense may be available for defendants suffering from chronic dissociative disorders—-such as dissociative identity disorder. In U.S. 
experts who are familiar with dissociative episodes, in cases where there is supporting evidence, would also argue that the disruptions in functioning could meet criteria for both insanity and incapacitation defenses (McFarlane, 1998). There is also at least one court decision that recognizes the availability of both incapacitation defense an acute dissociative episode of a military veteran suffering from PTSD (People v. Lisnow, 88 Cal. App. 3d Supp. 21, 151 Cal. Rptr. 621 (App. Dep't Super Ct. 1978)). This is due to the coexistence of both physical "loss of control" and the diminishing mental capacity to "distinguish between right and wrong." However, if there are no sufficient witness reports, it would be a matter of whether the defendant's account is viewed as credible by the jury and it would also depend on forensic examinations. Having a low DES score would not be important if more comprehensive evaluations of dissociative disorders were administered and were positive for the presence of dissociation. Even an evaluation of hypnotic capacity could help, as shown by Dell (2016), who states that hypnotic capacity is a "necessary diathesis for dissociation."

The availability of insanity and involuntariness/incapacity defenses for psychiatric conditions is not finely defined under Turkish criminal law code contrary to the U.S. law that adopts a stricter separation between the two. However, within the general framework that defines defences available for situations involving "diminished mental capacity," the Turkish criminal statute nevertheless contains language that may be interpreted in a way to allow a defense that resembles the incapacity defense available under the U.S. law. Under Turkish criminal code, the forensic/medical expert will have to testify either that 1) at the time of the conduct the individual could not comprehend the legal meaning and consequences of his or her act due to a psychiatric condition (diminishing of mental capacity to differentiate right or wrong), or 2) at the time of the conduct the capacity of the individual to direct his or her acts in relation to the conduct was substantially impaired (physical incapacitation). The second prong potentially provides an implied involuntary movement defence that may be more deferential and flexible than the first prong. 


\section{Clinical Aspects}

The connection between neonaticide and unperceived pregnancy is not clear yet. In one study on 32 cases of neonaticide, only two women had unperceived pregnancy (Vellut, Cook, \&Tursz , 2012). In another study, pregnancy was negated in 25 of 28 (89.3\%) cases, while two (7.1\%) women died immediately after delivery, so there was a lack of information on their motives (Amon et al., 2012). Spinelli (2001) reported with regard to 16 cases of neonaticide that nearly all of the women reported similar precipitants and symptoms, including depersonalization, dissociative hallucinations, and intermittent amnesia at delivery. Nine women reported a history of childhood sexual trauma, and seven of those reports were corroborated by independent sources. Six women reported a history of physical abuse. The women's scores on the DES (mean=28.9 within a possible range of 0-100) suggested a high level of chronic dissociative pathology. "Unawareness of pregnancy" has been reported in dissociative identity disorder (Van der Hart, Faure, Van Gerven, \& Goodwin, 1991). Indeed, an acute dissociative reaction may be superposed on a pre-existing chronic dissociative process (Tutkun, Yargic, \& Sar, 1996). However, in the present case, current evidence is not indicative of a pre-existing chronic dissociative disorder.

The role of dissociation in Maria's acute reaction to the unexpected delivery needs some clarification. Acute dissociative reactions are seen in psychologically traumatized populations (Spiegel et al., 2011). Recently, acute dissociative reaction to stressful events has been introduced as a new category among DSM-5's Other Specified Dissociative Disorders (OSDD). Symptoms such as amnesia, transient stupor, constriction of consciousness, and disorganized behavior are sufficient to warrant this diagnosis (American Psychiatric Association, 2013, p. 291). Experiencing the delivery as traumatizing and subsequently developing PTSD are rather prevalent (Haagen, Moerbeek, Olde, Van der Hart, \& Kleber, 2015). However, dissociative symptoms may also play a dominant role in any "partus stress reaction" (Moleman, Van der Hart, \&Van der Kolk, 1992), in particular during an unexpected delivery. This is an old label for acute dissociative reaction -not a 
normative phenomenon- specifically and during and/or right after the delivery. Moleman et al. (1992) described three cases of women for whom the delivery was a traumatic experience which manifested in dissociative and, in subsequent post-traumatic stress symptoms. These three women all had histories of infertility and complicated pregnancies. They all had feared that they would lose their babies and during the delivery had become panic-stricken in anticipation of what they thought would be an inevitably disastrous outcome. Panic ceased when they dissociated from both their subjective physical experience and from contact with their surroundings. Two of the three patients had amnesia for their delivery.

Orientation to reality during an acute dissociative reaction to unexpected delivery may be of vital importance for long-term psychiatric outcome. Another medico-legal case followed up by one of the authors (O.O.), one woman committed three neonaticides during acute dissociative reactions in the aftermath of her all three consecutive pregnancies. The babies' corpses found several years later. This observation suggested that a dissociation with regard to such events may last many years: the acute dissociative reactions led to persistent focal amnesia in these cases (Omay, 2016). In the presented case, the presence of Maria's friends during delivery and the acute dissociative reaction allowed some degree of reality orientation. Apart from the subsequent PTSD, this may have prevented a worse outcome in terms of chronification.

Denial of pregnancy still constitutes an enigma for psychiatry as it is a scarcely studied subject. There is no established evidence about increased prevalence of childhood trauma (e.g., sexual abuse) in cases of unperceived pregnancy. Given that sexual intercourse in non-married relationships is so widespread and accepted, at least in western countries where Maria is from, such an origin cannot be claimed as a main causal factor either. Explanations such as denial of fertility (Struye, Zdanowicz, Ibrahim, \& Reynaert, 2013) or an unconscious evolutionary wish of transmitting genes without being a mother (Sandoz, 2016) have been proposed. Denial of pregnancy is the somatic inverse of false pregnancy (pseudocyesis) which has a firm basis as a psychosomatic 
disorder (Kenner \& Nicholson, 2015). According to a recent review of related studies (Kenner \&Nicolson, 2015), abdominal muscle tone, persistent corpus luteum function, and reduced availability of biogenic amines contribute to false pregnancy while posture, fetal position, and corpus luteum insufficiency play a role in denial of pregnancy. For each condition, there are multiple reports in which the body reveals her true pregnancy status as soon as the woman is convinced of her diagnosis.

As no homogenous and scientifically proven cause has yet been established, we suggest another name for this condition, because "denial" suggests a motivational cause. Hence, using the term "denial" may add to the suffering of women and families concerned. "Unperceived pregnancy", the translation of "die nicht wahrgenommene Schwangerschaft" used by Wessel (1998) in his initial thesis in German, which is in line with Van der Hart et al.'s (1991) “unawareness of pregnancy" as well as with their construct of "non-realization," seems to be the best way to describe this condition in a rather neutral fashion. Beside its inherently dissociative nature (i.e., enduring disruption of bodily and cognitive perception), as a psychosomatic disorder of potential source for traumatic stress, unperceived pregnancy deserves to be a diagnostic category in female reproductive psychiatry in its own right (Beier, Wille, \& Wessel, 2006).

Last but not least, we would like to add an excerpt from Maria's recent testament to the authors (published by her permission) about her extraordinary experience here which reflects a tradegy made possible by the human nature: "It is really hard for me to describe how I feel about the denial of pregnancy. I know that, in the weeks following the birth, I asked myself a lot of questions about it. I felt betrayed by my body. I felt like my body was a part of me that I can't control. I thought that if my body did this to me, and hid all these things from me, I could not be certain about anything that I felt, or anything that I thought about me. The main feeling that I had, was to not trust myself anymore." 
Acknowledgement: The authors are grateful to Maria (pseudonym) for her permission in studying and publishing on her tragic personal and medico-legal story. Her sincere expressions have been most helpful in developing the main line of the present paper.

\section{REFERENCES}

American Psychiatric Association (2013). Diagnostic and statistical manual of mental disorders, $5^{\text {th }}$ ed. Washington DC: American Psychiatric Association.

Amon, S., Putkonen, H., Weizmann-Henelius, G., Almiron,M.P., Formann,A.K., Voracek,M., Friedrich, M., \& Klier, C.M. (2012). Potential predictors in neonaticide: The impact of the circumstances of pregnancy. Archives of Women's Mental Health, 15, 167-174.

Aydin, N. (2013). Do clinicians overlook denial of pregnancy in classification systems. Paper presented at the 3rd International Congress on Neurobiology, Psychopharmacology \& Treatment Guidance, Thessaloniki, Greece, 30 May-2 June.

Beier, K.M., Wille, R., \& Wessel, J. (2006). Denial of pregnancy as a reproductive dysfunction: a proposal for international classification systems. Journal of Psychosomatic Research, 61,723-730.

Dell, P. (2016). Is high hypnotizability a necessary diathesis for pathological dissociation? Journal of Trauma \& Dissociation

Haagen, J.F., Moerbeek, M., Olde, E., Van der Hart, O., \& Kleber, R.J. (2015). PTSD after childbirth: A predictive ethological model for symptom development. Journal of Affective Disorders, 185,135-143. 
Kenner, W.D., \& Nicolson, S.E. (2015). Psychosomatic disorders of gravida status: False and denied pregnancies. Psychosomatics, 56,119-128.

Moleman, N., Van der Hart, O., \& Van der Kolk, B.A. (1992) .The partus stress reaction: A neglected etiological factor in postpartum psychiatric disorders. Journal of Nervous and Mental Disease, 180, 271-272.

Omay, O. (2016).The most unexpected pregnancy, denial of pregnancy. Paper presented at the 8th International Conference of Psychopharmacology, Antalya, Turkey.

McFarlane, J.E. (1998). Neonaticide and the "ethos of maternity": traditional criminal law defenses and the novel syndrome. 5 Cardozo Women's Law Journal, 175, 1-60.

Sandoz, P. (2016). To transmit genes without becoming mother. An evolutionary conflict behind denial of pregnancy. PeerJ Preprints, https://doi.org/10.7287/peerj.preprints.1853v1

Şar, V. (2011). Developmental trauma, complex PTSD, and the current proposal of DSM-5. European Journal of Psychotraumatology, 2. doi:http://dx.doi.org/10.3402/ejpt.v2i0.5622

Şar, V., \& Ozturk, E. (2008). Psychotic symptoms in complex dissociative disorders. In A. Moskowitz, I. Schaefer, \& M. Dorahy (Eds.), Psychosis, trauma and dissociation: Emerging perspectives on severe psychopathology (pp.165-175) New York: Wiley. 
Spiegel, D., Lewis-Fernandez, R., Loewenstein, R., Şar V, Simeon, D., Vermetten, E., ...., Brown, R.J., \& Dell, P.F. (2011) . Dissociative disorders in DSM-5. Depression \& Anxiety, 28, 824-852.

Spinelli, M. G. (2001). A systematic investigation of 16 cases of neonaticide. American Journal of Psychiatry, 158, 811-813.

Struye, A., Zdanowicz, N., Ibrahim,C. \& Reynaert,C. (2013). Can denial of pregnancy be a denial of fertility? A case discussion. Psychiatria Danubina, 25, Suppl. 2, 113-117.

Tutkun, H., Yargıç, L.İ., \& Şar, V. (1996).Dissociative identity disorder presenting as hysterical psychosis. DISSOCIATION, 9, 241-249.

Van der Hart, O., Faure, H., Van Gerven, M., \&Goodwin, J.M. (1991). Unawareness and denial of pregnancy in patients with multiple personality disorder. DISSOCIATION, 4(2),65-73.

Van der Hart, O., \& Witztum, E. (2008). Dissociative psychosis: Clinical and theoretical aspects In A. Moskowitz, I. Schaefer, \& M. Dorahy (Eds.), Psychosis, trauma and dissociation: Emerging perspectives on severe psychopathology (pp. 165-175). New York: Wiley.

Vellut, N., Cook, J.M., \& Tursz, A. (2012). Analysis of the relationship between neonaticide and denial of pregnancy using data from judicial files. Child Abuse \&Neglect, 36, 553-563.

Wessel, J. (1998).Die nicht wahrgenommene (verdrängte) Schwangerschaft: Eine prospektive Untersuchung aus geburtsmedizinischer sicht unter Berücksichtigung endokrinologischer, psychosomatischer und epidemiologischer Aspekte. Charité, Humboldt University, Berlin. 
Wessel, J., \& Büscher, U. (2002). Denial of pregnancy: Population based study. British Medical Journal, 324 (7335), 458.

Yuce, H., Aydin,N., Omay, O., Kosan, Z., Gultekin, A.G., Aksoy, A., \& Wessel, J. (2015).

Prevalence of denial of pregnancy and associated factors in Turkey. Women's Mental Health, 18(2), 343. 